Results MT-67\% of visits aged 20-29 y; 94\% non-Hispanic whites. Annual visits increased $60 \%$-pre-intervention $(2004-2008) \bar{x}=438$ visits/y; post $(2009)=702$ visits. CT testing increased $44 \%$ (2004-2008 $\bar{x}=58 \%$ of visits/y tested; 2009: 78\% tested). Significant $(p<0.05)$ multivariate factors related to CT testing: intervention status $(A O R=2.21)$, racial/ethnic minority $(A O R=2.06)$, new client $(A O R=5.59)$, visit's federal funding ( $A O R=3.04)$, and clinic (Billings: $\mathrm{AOR}=0.45)$. $\mathrm{CT}+$ was $13.9 \%$. Factors related to

Abstract P1-S6.25 Table 1 Characteristics of male family planning client visits, CT testing and positivity-2004-2009†

\begin{tabular}{|c|c|c|c|c|}
\hline Characteristic & No. & Percent & $\begin{array}{l}\text { \% CT } \\
\text { Tested }\end{array}$ & $\begin{array}{l}\text { \% CT } \\
\text { Positive }\end{array}$ \\
\hline Grantee: Planned Parenthood of Montana & 2891 & 100 & 59 & 13.9 \\
\hline \multicolumn{5}{|l|}{ Clinic } \\
\hline Missoula & 2009 & 69 & $63^{*}$ & $13.6^{*}$ \\
\hline Billings & 882 & 31 & 51 & 14.6 \\
\hline \multicolumn{5}{|l|}{ Age (years) } \\
\hline$<20$ & 381 & 13 & $67^{*}$ & $17.8^{*}$ \\
\hline $20-24$ & 1217 & 42 & 60 & 17.3 \\
\hline $25-29$ & 700 & 25 & 60 & 10.5 \\
\hline$>29$ & 572 & 20 & 54 & 7.6 \\
\hline \multicolumn{5}{|l|}{ Race/ethnicity } \\
\hline Non-Hispanic white & 2730 & 94 & 59 & 13.7 \\
\hline Minority & 161 & 6 & 63 & 16.5 \\
\hline \multicolumn{5}{|l|}{ Intervention status } \\
\hline Pre (2004-2008) & 2189 & 76 & $54^{*}$ & 13.2 \\
\hline Post (2009) & 702 & 24 & 78 & 14.9 \\
\hline \multicolumn{5}{|l|}{ Insurance } \\
\hline No & 1995 & 69 & $58^{*}$ & $15.3^{*}$ \\
\hline Yes (public or private) & 896 & 31 & 62 & 11.0 \\
\hline \multicolumn{5}{|l|}{ Client status } \\
\hline New & 1316 & 60 & $77^{*}$ & 14.8 \\
\hline Continuing & 877 & 40 & 35 & 11.4 \\
\hline \multicolumn{5}{|l|}{ Federal Title $\mathrm{X}$ funding } \\
\hline No & 1873 & 65 & $49^{*}$ & $11.1^{*}$ \\
\hline Yes & 1018 & 35 & 78 & 16.1 \\
\hline $\begin{array}{l}\text { Grantee: Family Health Centers, } \\
\text { San Diego, CA } \neq\end{array}$ & 7008 & 100 & $31 \%$ & $6.4 \%$ \\
\hline \multicolumn{5}{|l|}{ Clinic } \\
\hline Logan & 4732 & 68 & 31 & $7.5^{*}$ \\
\hline Beach & 2276 & 32 & 32 & 4.3 \\
\hline \multicolumn{5}{|l|}{ Age (years) } \\
\hline$<20$ & 252 & 4 & $25^{*}$ & $14.6^{*}$ \\
\hline $20-24$ & 1334 & 19 & 32 & 9.7 \\
\hline $25-29$ & 1686 & 24 & 33 & 7.8 \\
\hline$>29$ & 3736 & 53 & 30 & 3.9 \\
\hline \multicolumn{5}{|l|}{ Grantee: FHC, San Diego cont. } \\
\hline \multicolumn{5}{|l|}{ Race/ethnicity } \\
\hline Non-Hispanic white & 1726 & 27 & 31 & $6.4^{*}$ \\
\hline Non-Hispanic black & 335 & 5 & 29 & 16.4 \\
\hline Hispanic & 4428 & 68 & 32 & 6.0 \\
\hline \multicolumn{5}{|l|}{ Intervention status } \\
\hline Pre (2004-2008) & 5773 & 82 & $29 *$ & 6.4 \\
\hline Post (2009) & 1235 & 18 & 41 & 6.5 \\
\hline \multicolumn{5}{|l|}{ Insurance } \\
\hline No & 2258 & 32 & $35^{*}$ & $2.7^{*}$ \\
\hline Yes (public or private) & 4749 & 68 & 29 & 7.6 \\
\hline \multicolumn{5}{|l|}{ Client status } \\
\hline New & 1979 & 28 & $44^{*}$ & $9.8^{*}$ \\
\hline Continuing & 5029 & 72 & 26 & 4.3 \\
\hline
\end{tabular}

${ }^{*}$ Statistically significant $(p<0.05)$ univariate differences.

†Calendar Year 2010 data available March 2011.

$\ddagger$ All FHC San Diego clinic visits are federal Title X funded; measure excluded from this grantee's results.
CT+: age $<20$ y $(A O R=2.44$, Ref: $>29$ y), no insurance $(A O R=1.67)$, and federal funding $(\mathrm{AOR}=1.76)$. Annual female FP clients were stable (2004-2008: 5085/y; 2009: 5650). SD-43\% of visits aged 20-29y; 66\% Hispanic. Annual visits increased 18\%-pre-intervention $\bar{x}=1045 / y$; post $=1235$ visits. CT testing increased $41 \%$ (pre: $\bar{x}=29 \%$ of visits/y tested; post: $41 \%$ tested). Factors related to testing: new client $(\mathrm{AOR}=2.39)$ and intervention status $(\mathrm{AO}=1.76)$. $\mathrm{CT}+$ was $6.4 \%$. Factors related to $\mathrm{CT}+$ : age $<20$ y $(\mathrm{AOR}=3.13)$, black race $(A O R=2.29)$, new client $(A O R=2.47)$, and clinic (Beach: $\mathrm{AOR}=0.40)$. Annual female FP clients were stable (2004-2008: 4440/y; 2009: 4833).

Conclusions Early data indicate FP clinic interventions significantly increased male clients and the proportion tested for CT without reducing female FP clients. Screening prioritised new male patients. Like other CT programs, young and minority males have increased infection risk. CT positivity varied by clinic, supporting use of local data to inform male STI services at FP clinics.

\section{P1-S6.26 MODELLING THE IMPACT OF RAPID TREPONEMAL TESTS ON SYPHILIS PREVALENCE AMONG FEMALE SEX WORKERS IN INDIA}

doi:10.1136/sextrans-2011-050108.250

${ }^{1} \mathrm{~S}$ Mishra, ${ }^{2} \mathrm{~S}$ Moses, ${ }^{1} \mathrm{M}$ Pickles, ${ }^{3} \mathrm{~B} \mathrm{M}$ Ramesh, ${ }^{3} \mathrm{~S}$ Isac, ${ }^{3} \mathrm{R}$ Washington, ${ }^{2} \mathrm{M}$ Becker, ${ }^{2} J$ Blanchard, ${ }^{1} \mathrm{M}$ C Boily. Imperial College, London, UK; ${ }^{2}$ Centre for Global Public Health, Canada; ${ }^{3}$ Karnataka Health Promotion Trust, Bangalore, India

Background Rapid treponemal tests performed at point-of-care (POC) are being used to scale up syphilis (Tp) screening in highprevalence resource-limited settings. However, their advantage over offsite rapid plasma reagin (RPR) may be offset by variable sensitivity when used as POC, and the potential for resurgence in infectious cases due to enhanced treatment of latent $\mathrm{Tp}$ and loss of acquired immunity. We compare the change in prevalence of infectious Tp using different screening methods within a community of female sex workers (FSWs) in Karnataka, India.

Methods We developed a deterministic model of heterosexual Tp transmission between FSWs and their clients. Test sensitivities were estimated against a reference laboratory RPR with a confirmatory test. Main outcomes included predicted changes in FSW and client infectious Tp prevalence at 30 years, and post-intervention rebound in infectious Tp.

Results Reductions in infectious Tp prevalence achieved by screening were highest in areas with low initial treponemal test positivity, and were relatively insensitive to variations in parameter assumptions. At least once a year screening with a $100 \%$ sensitive POC test reduced infectious prevalence to an equal or greater extent as compared to a $100 \%$ sensitive offsite RPR test. A paradoxical rebound in infectious prevalence was observed after start of POC or RPR screening in approximately half of scenarios but resurgence above pre-intervention levels was rare $(<5 \%$ of scenarios). Rebound was most likely in high-prevalence regions (treponemal test positivity $35-45 \%$ ), where it manifested after 3.5 to 8.6 years, depending on assumptions on duration of immunity and sex-work turnover, and could be prevented with screening every 3 months. The ability to detect resurgence depended on frequency of monitoring and size of the surveyed population. POC screening of variable sensitivity was equally or more effective at reducing $\mathrm{Tp}$ prevalence than offsite RPR (sensitivity 100\%) when follow-up was less than 50\% (POC sensitivity 70\%) and 70\% (POC sensitivity 95\%).

Conclusions Rapid treponemal POC tests have the potential to be as or more useful than offsite RPR tests within a high-risk population, when offsite RPR is unfeasible or return visits are 
low, irrespective of the sensitivity of available POC tests. In highprevalence settings, sufficient coverage and screening frequency must be maintained to avert an increase in infectious syphilis prevalence.

\section{P1-S6.27 COULD A PEER DRIVEN INTERVENTION INCREASE UPTAKE OF CHLAMYDIA SCREENING? PROOF OF PRINCIPLE}

\section{doi:10.1136/sextrans-2011-050108.251}

${ }^{1} \mathrm{P}$ Horner, ${ }^{2} \mathrm{~J}$ Loaring, ${ }^{1} \mathrm{H}$ Matthew, ${ }^{3} \mathrm{I}$ Oliver, ${ }^{1} \mathrm{R}$ Campbell, ${ }^{1} \mathrm{C}$ Trotter, ${ }^{1} \mathrm{~J}$ Macleod, ${ }^{4} \mathrm{~K}$ Pye. ${ }^{1}$ University of Birmingham, Birmingham, UK; ${ }^{2}$ University of Bristol, UK; ${ }^{3} \mathrm{Health}$ Protection Agency, UK; ${ }^{4}$ Bristol Primary Care Trust, UK

Background Uptake of the opportunistic National Chlamydia Screening Programme in England is low and below model estimates of the optimal level to reduce Chlamydia incidence. Peer led approaches may increase screening uptake but their feasibility and acceptability to young people is not known.

Methods Focus groups and interviews with young women and men. All participants had expressed an interest in undergoing Chlamydia screening or had already been screened. The focus group and interviews were audio taped and transcribed verbatim for analysis. Thematic analysis of the data was conducted to identify, compare and report patterns in the data. Following interview, Chlamydia postal kits were introduced to participants and their opinions on giving these out to their peers sought. Participants were asked for their views and experiences of discussing Chlamydia screening and distributing kits to their friends four to eight weeks after the focus group/interview. All kits returned over a 9-month period to the laboratory were recorded.

Results Six men (mean age 19 years) and 6 women (mean age 20 years) were recruited. In total 45 kits were distributed, $33(73 \%)$ to female participants. $26(79 \%)$ and $3(25 \%)$ of kits given to females and males respectively were given to peers. Of those tests distributed to peers there is a high return rate 34\% (10/29) all of which had been given out by females. On average, 1.7 kits were returned for each female participant. Participants generally felt positive about the idea of peer-driven screening using postal kits. However, embarrassment was a key theme, particularly among men. Generally women but not men were able to discuss Peer Driven Screening among their close friends. Both sexes felt Peer Driven Screening would be easier if kits were readily available in multiple sites, and Chlamydia screening was more widely promoted.

Conclusion Female Peer Driven Screening but not male Peer Driven Screening was successful in recruiting peers to participate in Chlamydia screening. A peer driven intervention may increase uptake of Chlamydia screening.

\section{P1-S6.28 INTEGRATED HIV, SYPHILIS, AND OTHER STI TESTING IN NORTH CAROLINA COUNTY JAILS}

doi:10.1136/sextrans-2011-050108.252

${ }^{1} \mathrm{~J}$ Scott, ${ }^{2} \mathrm{~L}$ A Sampson, ${ }^{2} \mathrm{~J} \mathrm{M}$ Clymore, ${ }^{1} \mathrm{P}$ R Moore, ${ }^{2} \mathrm{P}$ A Leone. ${ }^{1}$ Centers for Disease Control \& Prevention, Raleigh, USA; ${ }^{2}$ NC Division of Public Health, Raleigh, USA

Background In 1999 North Carolina initiated STI screening programs in seven county jails as part of the CDC Syphilis Elimination Effort (SEE). All jails were willing to permit screening programs for syphilis but only two also screened for HIV. In 2007 the SEE funding was depleted and the 7 SEE jail projects were converted to HIV screening under the CDC Expanded Testing Initiative (ETI). New jails were added $(n=21)$ and several have added screening for other STIs. Testing is supported by 10 local health departments and 5 non-traditional testing sites which assure treatment for STDs and make referrals for HIV care services.

Methods From January to June 2010, STI screening data for 28 jails was analysed. All jails tested for HIV and syphilis, one jail added HCV screening and another jail added NAAT testing for gonorrhoea and chlamydial infection. Reactive syphilis tests and positive HIV tests were verified against surveillance records to determine whether or not they were previous cases or newly diagnosed infections. Positive tests for Neisseria gonorrhoeae and Chlamydia trachomatis were considered to be new infections. Positive tests for HCV are considered prevalent infections. All data were analysed using SAS 9.1.3.

Results Under SEE, only two jails screened for both HIV and syphilis. From 2002 to 2005, 3626 inmates were screened. There were 46 (1.3\%) HIV-positive inmates and 158 (4.4\%) with reactive syphilis tests. Of those 158,30 were confirmed new syphilis cases $(0.83 \%$ case rate). Under ETI, 28 jails screened 4688 inmates for syphilis and 4662 for HIV in just 6 months (January-June, 2010, see Abstract P1-S6.28 table 1). HIV positivity rates were similar for men and women $(p=0.90)$ but women were more likely than men to be both a syphilis reactor (OR 4.8 95\% CI 2.8 to 8.2) and a new case (OR 5.9 95\% CI 1.9 to 17.9). Among all positive tests, there were no comorbid patients.

Abstract P1-S6.28 Table 1 HIV and STI testing in North Carolina County Jails, January-June, 2010

\begin{tabular}{|c|c|c|c|c|c|c|}
\hline \multirow[b]{2}{*}{ STI** } & \multicolumn{2}{|l|}{ Men } & \multicolumn{2}{|l|}{ Women } & \multicolumn{2}{|l|}{ All* } \\
\hline & Tested & Positive & Tested & Positive & Tested & Positive \\
\hline HIV & 3640 & $17(0.47 \%)$ & 1006 & $5(0.50 \%)$ & 4662 & $22(0.47 \%)$ \\
\hline New Cases*** & & $2(0.05 \%)$ & & $1(0.10 \%)$ & & $3(0.06 \%)$ \\
\hline Syphilis & 3633 & $24(0.66 \%)$ & 1000 & $31(3.10 \%)$ & 4688 & $55(1.18 \%)$ \\
\hline New Cases ${ }^{* * *}$ & & $5(0.14 \%)$ & & $8(0.80 \%)$ & & $13(0.28 \%)$ \\
\hline $\mathrm{HCV}$ & 201 & $11(5.47 \%)$ & 52 & $3(5.77 \%)$ & 253 & $14(5.53 \%)$ \\
\hline $\mathrm{Ct}$ & 202 & $14(6.93 \%)$ & 28 & 0 & 230 & $14(6.09 \%)$ \\
\hline Gc & 200 & 0 & 28 & $1(3.57 \%)$ & 228 & $1(0.44 \%)$ \\
\hline
\end{tabular}

*Includes transgender, missing sex. ${ }^{* *} \mathrm{n}=28$ jails tested for syphilis and HIV, 1 jail tested for $\mathrm{HCV}$ and a different jail tested for $\mathrm{Ct} / \mathrm{Gc}$. ${ }^{* *}$ New cases verified against surveillance data.

Conclusions The jail setting proves to be an important setting for detecting new syphilis cases, particularly among women, and for identifying HIV-positive inmates. Many of these HIV positives were not new diagnoses but may represent persons who need referrals for care and treatment. Screening for HCV and combined $\mathrm{Ct} / \mathrm{Gc}$ screening was also productive and should be expanded to other jails. Due to the high concentration of persons who trade sex for drugs or money in jail settings, it is especially important that these HIV and STI cases be identified and referred for treatment and partner services to prevent ongoing transmission.

\section{P1-S6.29 LONGITUDINAL TRENDS IN HIV TESTING AND PREVALENCE AMONG STI CLINIC PATIENTS IN LILONGWE, MALAWI: 2006-2010}

doi:10.1136/sextrans-2011-050108.253

${ }^{1} \mathrm{~K}$ Powers, ${ }^{2} \mathrm{G}$ Kamanga, ${ }^{2} \mathrm{C}$ Mapanje, ${ }^{2} \mathrm{~J} \mathrm{~K}$ Malava, ${ }^{2} \mathrm{M}$ Chindebvu, ${ }^{2} \mathrm{H}$ Kamzati, ${ }^{2} \mathrm{~F}$ Martinson, ${ }^{1} \mathrm{~W}$ Miller, 'M Cohen, ${ }^{1} \mathrm{I}$ Hoffman. ' University of North Carolina, Chapel Hill, USA; ${ }^{2}$ UNC Project Malawi, Lilongwe, Malawi

Background To understand longitudinal trends in HIV status awareness, HIV test acceptance, and HIV prevalence among 